University of Nebraska - Lincoln

DigitalCommons@University of Nebraska - Lincoln

$5-11-2005$

\title{
Magnetic behavior of Sm-Co-based permanent magnets during order/disorder phase transformations
}

\author{
Shampa Aich \\ University of Nebraska - Lincoln, saich2@unl.edu \\ J. Kostogorova \\ University of Nebraska - Lincoln \\ Jeffrey E. Shield \\ University of Nebraska - Lincoln, jshield@unl.edu
}

Follow this and additional works at: https://digitalcommons.unl.edu/cmrafacpub

Part of the Nanoscience and Nanotechnology Commons

Aich, Shampa; Kostogorova, J.; and Shield, Jeffrey E., "Magnetic behavior of Sm-Co-based permanent magnets during order/disorder phase transformations" (2005). Faculty Publications from Nebraska Center for Materials and Nanoscience. 6.

https://digitalcommons.unl.edu/cmrafacpub/6

This Article is brought to you for free and open access by the Materials and Nanoscience, Nebraska Center for (NCMN) at DigitalCommons@University of Nebraska - Lincoln. It has been accepted for inclusion in Faculty Publications from Nebraska Center for Materials and Nanoscience by an authorized administrator of DigitalCommons@University of Nebraska - Lincoln. 


\title{
Magnetic behavior of Sm-Co-based permanent magnets during order/disorder phase transformations
}

\author{
S. Aich, J. Kostogorova, and J. E. Shield ${ }^{\text {a) }}$ \\ Department of Mechanical Engineering and Center for Materials Research and Analysis, \\ University of Nebraska, Lincoln, Nebraska 68588-0656
}

(Presented on 9 November 2004; published online 11 May 2005)

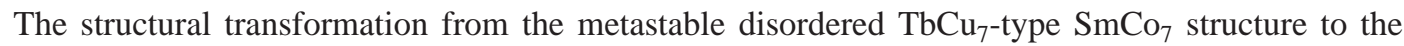
equilibrium ordered $\mathrm{Th}_{2} \mathrm{Zn}_{17}$-type $\mathrm{Sm}_{2} \mathrm{Co}_{17}$ structure was revealed by $\mathrm{x}$-ray diffraction analysis using Reitveld refinement. The magnetic properties depended strongly on the stage of the transformation, as the coercivity strongly depended on the annealing temperature. The as-solidified alloy in the $\mathrm{TbCu}_{7}$-type structure had a coercivity of $4 \mathrm{kOe}$, which increased to greater than $9 \mathrm{kOe}$. The coercivity decreased to around $5 \mathrm{kOe}$ as the transformation neared completion upon annealing at higher temperatures. The magnetization processes were also strongly influenced by the structural state. Initially it was totally controlled by nucleation followed by the domain wall pinning-controlled magnetization process. (C) 2005 American Institute of Physics.

[DOI: 10.1063/1.1855471]

\section{INTRODUCTION}

The influence of order-disorder transformations on the magnetic properties of the materials is highly significant in a number of magnetic alloy systems, as this transformation is related to the development of antiphase boundaries. In the $\mathrm{Fe}-\mathrm{Pt}$ system, improved coercivity was observed as the amount of order increased. ${ }^{1}$ However, the coercivity decreased significantly as the ordering transformation went to completion, suggesting the importance of the stage of the transformation in determining the magnetic properties. Order-disorder transformations also occur in rare-earthtransition metal compounds, from the metastable $\mathrm{TbCu}_{7}$-type structure to the $\mathrm{Th}_{2} \mathrm{Zn}_{17}$-type or $\mathrm{Th}_{2} \mathrm{Ni}_{17}$-type structures. ${ }^{2,3}$ This ordering involves the placement of transition metal "dumbbells" in the superstructure. In the Sm-Fe-N system, the transformation, and the microstructural changes associated with it, influenced the magnetic properties. ${ }^{4-8}$ In the $\mathrm{Sm}-\mathrm{Co}$ system, two related equilibrium phases form in Corich compositions: the $\mathrm{CaCu}_{5}$-type $\mathrm{SmCo}_{5}$ structure and the $\mathrm{Th}_{2} \mathrm{Zn}_{17}$-type $\mathrm{Sm}_{2} \mathrm{Co}_{17}$ structure. The $\mathrm{Sm}_{2} \mathrm{Co}_{17}$ structure is related to the $\mathrm{SmCo}_{5}$ structure through the ordered substitution of one-third of the Sm atoms by a pair of $\mathrm{Co}$ atoms (commonly referred to as Co dumbbells). ${ }^{9}$ The unit cell parameters are thus related with $c_{2: 17}=3 c_{1: 5}$ and $a_{2: 17}=\sqrt{ } 3 a_{1: 5}$. The dumbbell arrangement can also be randomized on the rare earth sites, which results in the disordered metastable $\mathrm{TbCu}_{7}$-type $\mathrm{SmCo}_{7}$ structure, which has the same unit cell as the $\mathrm{CaCu}_{5}$ structure. ${ }^{10}$

The suppression of the long-range order, leading to the formation of the $\mathrm{TbCu}_{7}$-type $\mathrm{SmCo}_{7}$ structure, has been accomplished by different processing routes, such as melt spinning, ${ }^{11}$ splat cooling, ${ }^{12}$ mechanical alloying, ${ }^{13}$ and dilute additions of $\mathrm{Zr}$ and $\mathrm{Ti}$ (Refs. 14-16) which has provided pathways to the development of materials with novel struc-

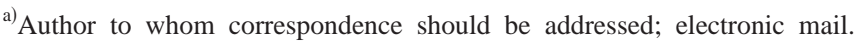
jshield2@unl.edu
}

tures, exemplified by recent advancements in elevatedtemperature performance of Sm-Co-based materials. The structures arise from the development of the ordered 2:17 structure, which produces microstructures that strongly pin Bloch walls. However, formation of appropriate microstructures is generally thought to depend on complex alloying additions, notably $\mathrm{Zr}$ and $\mathrm{Cu}$. Less research has been directed at understanding the order-disorder transformation effects on the magnetic properties in the Sm-Co alloy system. In this paper, we report the changes in magnetic behavior of rapidly solidified Sm-Co permanent magnets of simple binary alloy systems modified with $\mathrm{Nb}$ and $\mathrm{C}$ additions during orderdisorder phase transformations. An increase in coercivity is associated with the development of stronger pinning in partially ordered structures.

\section{EXPERIMENTAL PROCEDURES}

An alloy with nominal composition $\left(\mathrm{Sm}_{0.12} \mathrm{Co}_{0.88}\right)_{94} \mathrm{Nb}_{3} \mathrm{C}_{3}$ was made from high purity $(99.99 \%)$ elements by arc melting in a high purity argon atmosphere. Before arc melting 5\% extra $\mathrm{Sm}$ was added to the sample to compensate for the weight loss due to Sm vaporization during arc melting. The ingot was then rapidly solidified by melt spinning in high-purity argon at a chamber pressure of $1 \mathrm{~atm}$ and a tangential wheel velocity of $40 \mathrm{~m} / \mathrm{s}$. For annealing, the ribbons were first wrapped in tantalum foil and then were sealed in quartz capsules after repeated evacuations under ultra-high purity (UHP) Ar. The heat treatments at temperatures ranging from $700{ }^{\circ} \mathrm{C}$ to $900{ }^{\circ} \mathrm{C}$ were for $15 \mathrm{~min}$, followed by a water quench. The samples were then analyzed by x-ray diffraction using a Philips x-ray machine with $\mathrm{Cu}$ $K \alpha$ radiation. The powdered samples were mounted on an off-cut $\mathrm{SiO}_{2}$ single crystal to avoid the diffraction effects of the sample holder, or an amorphous $\mathrm{SiO}_{2}$ slide. The magnetic measurements were made by Superconducting quantum interference device magnetometry at $300 \mathrm{~K}$ utilizing a quantum design MPMS with maximum field of $7 \mathrm{~T}$. Magnetic 


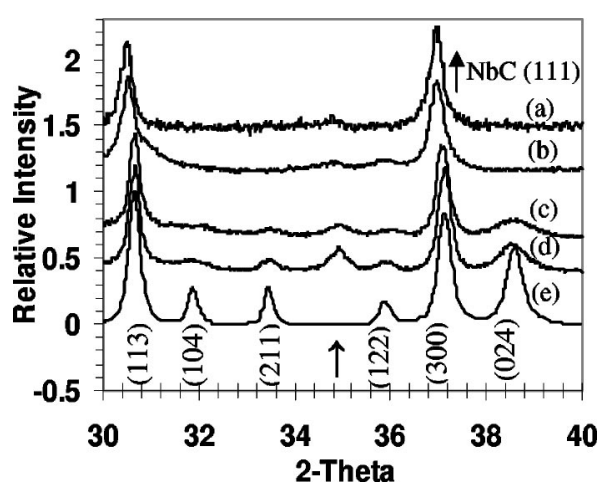

FIG. 1. X-ray diffraction scans of (a) the as-solidified Sm-Co-Nb-C alloy, and after heat treatment at (b) $750{ }^{\circ} \mathrm{C}$, (c) $850{ }^{\circ} \mathrm{C}$, and (d) $900{ }^{\circ} \mathrm{C}$. (e) Calculated diffraction pattern for $\mathrm{Sm}_{2} \mathrm{Co}_{17}$.

measurements were made on several ribbon pieces mounted so that the magnetic field was applied in the plane of the ribbon. Both x-ray diffraction and in- and out-of-plane magnetic measurement revealed an isotropic grain arrangement. ${ }^{17}$

\section{RESULTS AND DISCUSSIONS}

The addition of $\mathrm{Nb}$ and $\mathrm{C}$ influences the structure. $\mathrm{Nb}$ tends to reduce the amount of long-range order, ${ }^{8}$ while $\mathrm{C}$ reduces the scale of the microstructure. ${ }^{8,17}$ The $\mathrm{x}$-ray diffraction scan of the as-solidified alloy revealed the presence of only the $\mathrm{TbCu}_{7}$-type $\mathrm{SmCo}_{7}$ phase, and Rietveld analysis using the structural parameters in Ref. 10 fit well. No evidence of the $\mathrm{Th}_{2} \mathrm{Zn}_{17}$-type structure was found. Heat treatment, however, led to the recovery of the equilibrium $\mathrm{Sm}_{2} \mathrm{Co}_{17}$ structure due to a order/disorder transformation. The transformation is indicated by the development of superlattice diffraction peaks that result from the formation of long-range dumbbell ordering (Fig. 1). Initial development of order involves formation of the (122) diffraction peak and a shoulder on the (113) fundamental peak, which subsequently disappears at higher annealing temperatures [Fig. 1(b)]. This suggests the possibility of longer-ranged order (i.e., an intermediate structural state) in the transformation path. The superlattice diffraction peaks continue to increase in intensity upon heat treatment at higher temperatures. Finally, after annealing at $900{ }^{\circ} \mathrm{C}$ the four ordered peaks $(024)$ at $2 \theta=38.5^{\circ},(122)$ at $2 \theta=35.9^{\circ},(211)$ at $2 \theta=33.5^{\circ}$, and (104) at $\theta=31.9^{\circ}$ are very clearly developed, denoting the ordered $\mathrm{Th}_{2} \mathrm{Zn}_{17}$-type $\mathrm{Sm}_{2} \mathrm{Co}_{17}$ structure at that temperature. The x-ray diffraction pattern of the sample annealed at $900{ }^{\circ} \mathrm{C}$ compares favorably with the calculated pattern [Fig. $1(\mathrm{e})]$, although the reduced intensity of the superlattice peaks indicate that the transformation has not gone to completion. Additionally, heat treatment led to the precipitation of $\mathrm{NbC}$, as indicated by the formation of $\mathrm{NbC}$ diffraction peaks (indicated by the arrow in Fig. 1 at $\sim 34.8^{\circ} 2 \theta$ ). As the $\mathrm{NbC}$ precipitate forms, $\mathrm{Nb}$ and $\mathrm{C}$ are removed from solid solution in the Sm-Co structure. As a result the lattice parameter decreases and the peak positions shift.

The magnetic properties of the heat-treated samples changed significantly with the specific heat treatment temperature. Notably, a significant improvement in coercivity

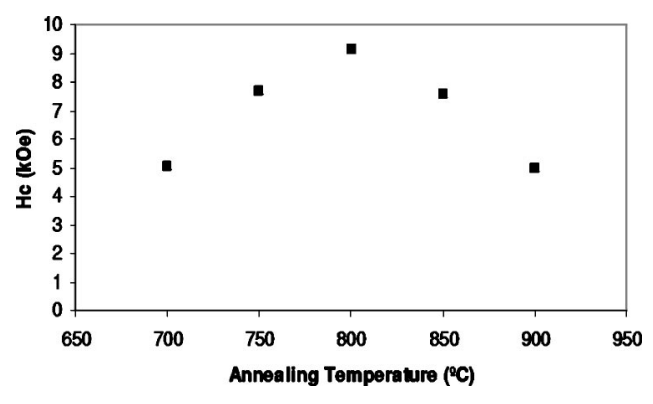

FIG. 2. Relationship between annealing temperature and intrinsic coercivity (for as-solidified ribbon $H_{\mathrm{c}}=4 \mathrm{kOe}$ ).

was observed (Fig. 2). The coercivity increased with annealing temperature, reaching a maximum at $800^{\circ} \mathrm{C}\left(H_{\mathrm{c}}\right.$ $=9.1 \mathrm{kOe}$ ), and then decreased upon annealing at $850{ }^{\circ} \mathrm{C}$ and $900{ }^{\circ} \mathrm{C}$, reaching $5 \mathrm{kOe}$ after the latter heat treatment. The initial magnetization behavior was also observed to change dramatically. In a thermally demagnetized state, the initial magnetization curves of samples in the as-solidified state and the early stages of the transformation showed a steep linear response to the applied field. The observation of a steep response in initial magnetization curves is consistent with initial magnetization by nucleation processes. ${ }^{18}$ However, as the transformation proceeded the initial magnetization curves displayed a lower initial susceptibility and a behavior more closely associated with domain wall pinning-controlled magnetization processes (Fig. 3). The decrease of slope in the initial magnetization curves, especially for the sample annealed at $800{ }^{\circ} \mathrm{C}$, clearly indicates a much stronger propensity for domain wall pinning.

The changes in both the coercivity and the initial magnetization behavior are associated with the structural and microstructural changes induced during the heat treatments. For example, the development of long-range order leads to the formation of antiphase domains/boundaries (APB/APD), which can act as pinning centers for Bloch walls. An increase in coercivity was attributed to Bloch wall pinning by APBs in the similar $\mathrm{Sm}-\mathrm{Fe}-\mathrm{N}$ system, ${ }^{8}$ and the cellular structure found in Sm-Co-based magnets ${ }^{19-21}$ that leads to strong Bloch wall pinning is essentially a domain structure with ordered and disordered regions. The development of pinning sites is also consistent with the initial magnetization curves, which showed stronger pinning-type behavior once partial long-range order developed. The decrease in coercivity can be related to grain growth that occurs at higher temperatures

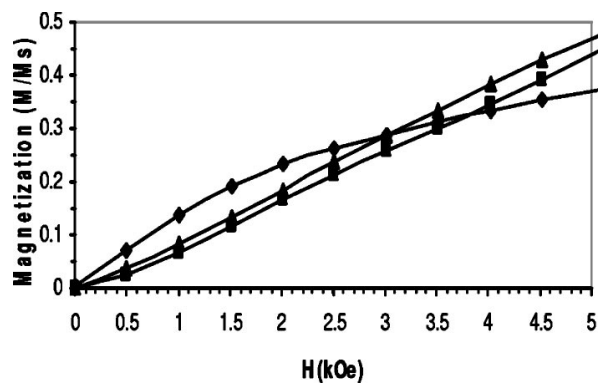

FIG. 3. The normalized curves showing initial magnetization behavior at different annealing temperatures $\left(\boldsymbol{\Delta}\right.$, as solidified; $\boldsymbol{\square}, 900{ }^{\circ} \mathrm{C}$; and $\bullet$, $\left.800{ }^{\circ} \mathrm{C}\right)$. 
and/or a decreased defect density as the transformation proceeded further, which increases APD size. The general behavior of the coercivity vs annealing temperature curve of Fig. 2 is also consistent with that reported in Ref. 22 for $\mathrm{Sm}-\mathrm{Co}-\mathrm{Fe}-\mathrm{Cu}-\mathrm{Zr}$ alloys but with different annealing times, with similar maximum coercive forces. In our alloys, we do not have $\mathrm{Cu}$ or $\mathrm{Zr}$, suggesting that these are not critical for the formation of appropriate structures that have strong pinning characteristics.

\section{CONCLUSIONS}

The transformation from the disordered $\mathrm{TbCu}_{7}$-type $\mathrm{SmCo}_{7}$ structure to the ordered $\mathrm{Th}_{2} \mathrm{Zn}_{17}$-type $\mathrm{Sm}_{2} \mathrm{Co}_{17}$ structure was found to greatly influence the magnetic behavior. An initial increase in coercivity was observed, which was followed by a decrease at higher heat treatment temperatures. The initial magnetization curves were also affected by the structural state. With no long-range order, the initial magnetization curves suggest nucleation-controlled magnetization processes, while partially ordered $\mathrm{Sm}_{2} \mathrm{Co}_{17}$ displayed initial magnetization curves with pinning characteristics. The magnetic behavior suggests that antiphase boundaries that develop during the ordering process act as pinning centers.

\section{ACKNOWLEDGMENTS}

The authors are grateful to the National Science Foundation for support of this work under Grant No. DMR0305354. The authors also appreciate facility support from QSPINS, the Materials Research Science and Engineering Center at the University of Nebraska.
${ }^{1}$ K. Watanabe and H. Masumoto, Trans. Jpn. Inst. Met. 26, 362 (1985).

${ }^{2}$ K. H. J. Buschow and A. S. vander Goot, Acta Crystallogr., Sect. B: Struct. Crystallogr. Cryst. Chem. 27, 1085 (1971).

${ }^{3}$ G. Boucher, J. Laforest, R. Lemaire, and J. Schweizer, C. R. Math. 262, 1 (1996).

${ }^{4}$ B. E. Meacham and J. E. Shield, J. Appl. Phys. 87, 6707 (2000).

${ }^{5}$ M. Katter, J. Wecker, and L. Schultz, J. Appl. Phys. 70, 3188 (1991).

${ }^{6}$ F. E. Pinkerton and C. D. Fuerst, Appl. Phys. Lett. 60, 2558 (1992).

${ }^{7}$ B. E. Meacham, J. E. Shield, K. W. Dennis, and R. W. McCallum, Advanced Hard and Soft Magnetic Materials, edited by L. H. Lewis et al. (MRS, Warrendale, PA, 1999), Vol. 577, p. 327.

${ }^{8}$ J. E. Shield, B. B. Kappes, B. E. Meacham, K. W. Dennis, and M. J. Kramer, J. Alloys Compd. 351, 106 (2003).

${ }^{9}$ W. E. Wallace, Prog. Solid State Chem. 16, 127 (1985).

${ }^{10}$ Y. Khan, Acta Crystallogr., Sect. B: Struct. Crystallogr. Cryst. Chem. 29, 2502 (1973)

${ }^{11}$ H. Saito, M. Takahashi, T. Wakiyama, G. Kodoand, and H. Nakagawa, J. Magn. Magn. Mater. 82, 322 (1989).

${ }^{12}$ K. H. Buschow and F. J. A. den Breeder, J. Less-Common Met. 3, 191 (1973).

${ }^{13}$ M. Q. Huang, W. E. Wallace, M. McHenry, Q. Chen, and B. M. Ma, J. Appl. Phys. 83, 6718 (1998).

${ }^{14}$ M. Q. Huang, M. Drennan, W. E. Wallace, M. E. McHenry, Q. Chen, and B. M. Ma, J. Appl. Phys. 85, 5663 (1999).

${ }^{15}$ J. Zhou, I. A. Al-Omari, J. P. Liu, and D. J. Sellmyer, J. Appl. Phys. 87, 5299 (2000).

${ }^{16}$ S. Aich and J. E. Shield, J. Magn. Magn. Mater. 279, 76 (2004).

${ }^{17}$ J. E. Shield, S. Aich, A. Hsaio and L. H. Lewis, Scr. Mater. 52, 75 (2004).

${ }^{18}$ A. Hsiao, S. Aich, L. H. Lewis, and J. E. Shield, IEEE Trans. Magn. 40, 2913 (2004)

${ }^{19}$ A. Yan, A. Bollero, K. H. Müller, and O. Gutfleisch, J. Appl. Phys. 91, 8825 (2002).

${ }^{20}$ A. Yan, O. Gutfleisch, A. Handstein, T. Gemming, and K. H. Müller, J. Appl. Phys. 93, 7975 (2003).

${ }^{21}$ A. Yan, A. Bollero, K. H. Müller, and O. Gutfleisch, Appl. Phys. Lett. 80, 1243 (2002).

${ }^{22}$ I. Panagiotopoulos, T. Matthias, D. Niarchos, and J. Fidler, J. Magn. Magn. Mater. 247, 355 (2002). 